\title{
The Epidemiology of Acute Respiratory Distress Syndrome Before and After Coronavirus Disease 2019
}

\author{
Kathryn W. Hendrickson, MD ${ }^{a, b}$, Ithan D. Peltan, MD, MSc ${ }^{a, c}$, \\ Samuel M. Brown, MD, MS ${ }^{a, b, *}$
}

\section{KEYWORDS}

- ARDS • Epidemiology • Incidence • Subtypes • Mortality • COVID-19

\section{KEY POINTS}

- Acute respiratory distress syndrome (ARDS) is heterogeneous.

- ARDS has high incidence among intensive care unit patients.

- ARDS has high morbidity and mortality.

- Improved supportive care has decreased ARDS incidence and mortality.

- Coronavirus Disease 2019-associated ARDS is a syndrome within the known ARDS spectrum.

\section{INTRODUCTION}

Acute respiratory distress syndrome (ARDS) occurs when a diverse array of triggers cause acute, bilateral pulmonary inflammation and increased pulmonary capillary permeability leading to acute hypoxemic respiratory failure. Pulmonary biopsy (or autopsy) classically demonstrates diffuse alveolar damage (DAD). ${ }^{1}$ Recognizing that ARDS is a syndrome and that research and benchmarking require reproducible definitions, a 2011 consensus conference in Berlin proposed a practical, updated definition (the "Berlin Definition"), ${ }^{2}$ In summary, this requires,

\footnotetext{
${ }^{a}$ Division of Pulmonary and Critical Care Medicine, Department of Medicine, University of Utah School of Medicine, 26 North 1900 East, Salt Lake City, UT 84112, USA; ${ }^{\text {b }}$ Division of Pulmonary and Critical Care Medicine, Department of Medicine, Intermountain Medical Center; ${ }^{\mathrm{C}}$ Pulmonary Division, Department of Medicine, Intermountain Medical Center, 5121 South Cottonwood Street, Murray, UT 84107, USA

* Corresponding author. Pulmonary Division, Department of Medicine, Intermountain Medical Center, 5121 South Cottonwood Street, Murray, UT 84107.

E-mail address: Samuel.Brown@imail.org
} 
1. An acute process developing within 1 week of a known clinical insult or new or worsening respiratory symptoms;

2. Radiographic images showing bilateral opacities not fully explained by effusions, lobar or lung collapse, or nodules; and

3. Impairment in oxygenation as measured by a $\mathrm{PaO}_{2} / \mathrm{Fio}_{2} \leq 300 \mathrm{~mm} \mathrm{Hg}$ in the presence of a positive end-expiratory pressure (PEEP) of at least $5 \mathrm{~cm} \mathrm{H} 2 \mathrm{O}$.

Despite many advances in the understanding of ARDS, morbidity and mortality remain high with few targeted therapies. In this epidemiologic review, we consider the etiology, subtypes and phenotypes, incidence, mortality, long-term outcomes, and the relationship(s) between Coronavirus Disease 2019 (COVID-19) and prepandemic ARDS.

\section{ETIOLOGY}

Admitting that patients would not have survived long enough to be diagnosed with ARDS before the widespread use of intensive care unit (ICU) ventilators for hypoxemic respiratory failure, Ashbaugh and colleagues first reported on ARDS as a distinct syndrome in a 1967 series of 12 patients. ${ }^{3}$ Despite suffering from heterogeneous primary insults, the patients all developed similar patterns of acute-onset respiratory failure with bilateral infiltrates and decreased pulmonary compliance accompanied by autopsy findings of acute inflammation and hyaline membranes. ${ }^{3}$

This initial report captured the heterogeneity of ARDS that continues to present challenges in diagnosis and treatment. Pneumonia is the most common trigger for ARDS, although nonpulmonary sepsis, aspiration pneumonitis, and trauma are also common. An assortment of less common triggers have been identified including pancreatitis and blood transfusion. Clinical syndromes compatible with ARDS but with no identifiable trigger are referred to as acute interstitial pneumonia (AIP) or sometimes HammanRich syndrome rather than ARDS and may represent a response to an array of sometimes overlapping pulmonary insults. ${ }^{1,4-15}$ In both ARDS and, presumptively, AIP, an insult elicits an inflammatory response which leads to increased-permeability pulmonary edema creating the hypoxemia and bilateral opacities on imaging required for diagnosis. ${ }^{16,17}$ In its most severe forms, DAD results pathologically.

ARDS resulting from direct pulmonary insult such as pneumonia manifests pathologically as alveolar collapse, fibrinous exudate, and edema of the alveolar walls to a greater degree than ARDS resulting from nonpulmonary causes such as pancreatitis. ${ }^{18}$ This may represent a spectrum of severity or alternative pathophysiological processes. What is less clear is why some patients with inciting conditions develop ARDS while others do not, and whether differences in genotype, phenotype, or therapeutic context play a role remains unclear.

Chronic conditions including obesity and diabetes have been associated with a decreased incidence of ARDS. In diabetes, some hypothesize that this observed association reflects a decreased inflammatory response among diabetics. ${ }^{19,20}$ A potential association with obesity is less clear. ${ }^{21-23}$ Importantly, collider bias may in fact account for the observed associations. ${ }^{24}$

On the contrary, chronic alcohol use has been associated with higher risk of ARDS. Kaphalia and Calhoun ${ }^{25}$ found that chronic alcohol use leads to pulmonary immune dysfunction, epithelial dysfunction, and the inability to handle reactive oxygen species leading to the high permeability pulmonary edema and hyaline membrane formation seen in ARDS. Smoking is also associated with higher risks of ARDS. Not only are patients who smoke more likely to get pneumonia they also have higher rates of ARDS triggered by nonpulmonary causes. ${ }^{26,27}$ Cigarette smoking may thus increase the 
risk of the inflammatory cascade that results in ARDS. Interestingly, ozone exposure (but no other known pollutants) is also associated with increased risk of ARDS. ${ }^{28}$ Consistently, older age, ${ }^{8}$ non-white race (likely a surrogate for "social determinants of disease"), ${ }^{29}$ and some genetic variants ${ }^{30}$ have been described as host factors associated with risk of developing ARDS.

Although age is a risk factor for developing ARDS, it has not consistently been found to be associated with increased mortality. The multinational LUNG-SAFE (The Large Observational Study to Understand the Global Impact of Severe Acute Respiratory Failure) study showed older age to be a risk factor for mortality ${ }^{31}$; however, when controlling for risk, severity, and comorbidity, the independent relationship between age and mortality in ARDS is not consistent. ${ }^{8}$ The association of race and ethnicity with ARDS mortality was studied in a retrospective cohort study in 2009 using patient data from three ARDS network randomized control trials. Black race and Hispanic ethnicity were found to have not only higher rates of ARDS than white individuals but higher mortality as well. The causes of race- and ethnicity-related differences are not well understood and likely vary between groups but, in all cases, likely derive substantially from "social determinants of disease" rather than genetic factors. For instance, the fact that higher mortality in Black patients resolves with adjustment for illness severity suggests barriers that hinder Black individuals from seeking early care, physician delay in diagnosis, and other factors worsen the severity mix in these groups. ${ }^{29}$

\section{SUBTYPES}

A defining characteristic of ARDS is its heterogeneity, from Ashbaugh's initial publication to the present day. ${ }^{32,33}$ Traditional categorizations (as, eg, in the Berlin definition) are based on severity of hypoxemia, which correlates with mortality and the extent of DAD on pathologic examination. ${ }^{34,35}$ The effects of some potential ARDS therapies may also vary with hypoxemia severity. For example, in 2018, Guo and colleagues ${ }^{36}$ published a systemic review and meta-analysis showing a likely trend toward improved outcomes in patients receiving a high-PEEP protocol. For patients with a $\mathrm{PaO}_{2} / \mathrm{FiO}_{2}(\mathrm{P} / \mathrm{F})$ ratio $\leq 200$, there was a slightly lower risk of death; however, in patients with a P/F ratio 201 to 300 , there was a possible higher risk of death. Of note this mortality benefit has not been seen in any individual randomized control trials ${ }^{37-39}$ and remains a controversial topic. Another example is the 2019 study of therapeutic neuromuscular blockade to improve outcomes in ARDS. Although a previous trial hinted at decreased mortality in patients with $\mathrm{P} / \mathrm{F}$ ratio less than $130,{ }^{40}$ this larger trial concluded no mortality benefit. ${ }^{41}$

ARDS can also be subdivided based on the initial insult, whether pulmonary (pneumonia, pulmonary contusion, and aspiration) or extrapulmonary (nonthoracic trauma, nonpulmonary sepsis, and transfusion). ${ }^{7,42,43}$ Several pathologic, biologic, and physiologic differences have been identified on this basis. ${ }^{18,44-47}$ However, in practice, it is difficult to differentiate between the two groups based on substantial overlap. ${ }^{13}$ These pathologic, biologic, and physiologic differences are heavily influenced by underlying lung function and architecture, smoking status, chronic diseases, and other conditions, which inflate the heterogeneity of ARDS. No mortality difference has been found between the two groups, likely related to the complexities of the overlap between the two groups. ${ }^{48}$

More recently, "machine learning"-style techniques have been used to identify distinct subtypes. Post-hoc analysis (using latent class analysis) of the ARMA (ARDSnet: Ventilation with Lower Tidal Volumes as Compared with Traditional Tidal Volumes for Acute Lung Injury and the Acute Respiratory Distress Syndrome) and ALVEOLI (Assessment of Low Tidal Volume and Elevated End-Expiratory Pressure to Obviate Lung Injury) 
trials revealed two phenotypes of ARDS. ${ }^{37,49}$ Relative to phenotype 1, phenotype 2 was hyperinflammatory, with higher plasma levels of inflammatory biomarkers, a higher prevalence of vasopressor use, lower serum bicarbonate, and a higher prevalence of sepsis found in phenotype 2 than in phenotype $1 .{ }^{50}$ Critically, in terms of its clinical utility, this hyperinflammatory phenotype was also associated with higher mortality. Phenotype may also predict response to therapies: A post-hoc analysis of a randomized controlled trial of statin therapy for ARDS suggested benefit for hyperinflammatory patients. ${ }^{51}$ It will be important with the expanding use of novel statistical techniques for subtyping to ground them in reality and validate them in both prospective cohorts and within prespecified subgroups in prospective trials.

\section{INCIDENCE}

The incidence of ARDS varies globally by over $400 \% .^{52}$ It is important to acknowledge in this context that ARDS as a syndrome reflects both patient physiology and clinical context. For example, where patients with hypoxemic respiratory failure are not routinely intubated (as may occur in certain institutional settings in USA/Europe or in low- and middle-income country settings with limited supplies of ventilators and/or resources and personnel for ICU-level care), ARDS incidence may appear lower than it actually is. Similarly, routine use of high-tidal-volume ventilation among patients at risk may increase the incidence of ARDS in a given setting. With those caveats in mind, incidence ranges from 10.1/100,000/y in Brazil in 2014 to 82/100,000/y in the United States in 2005 (Table 1). ${ }^{5,7,8,10}$ Between-study differences in case ascertainment and local context may drive these observed differences. ${ }^{53,54}$ Some studies, for instance, relied on clinician diagnosis while others used billing codes, both of which may be inaccurate. Both methods are likely to undercount ARDS cases, as only $60 \%$ of ARDS cases were appropriately identified by clinicians in one large study. ${ }^{1}$ Differences in the prevalence of ARDS risk factors may account for some of the variation as well.

Likely the highest quality evidence on ARDS incidence and management patterns originates from LUNG-SAFE, a prevalence study conducted during a 4-week period in 459 ICUs in 50 countries. Overall, $10 \%$ of all ICU patients and $23 \%$ of mechanically ventilated patients met ARDS criteria, yielding an ICU incidence of 5.5 cases per ICU bed per year.

In 2011, the Prevention and Early Treatment of Acute Lung Injury (PETAL) Network developed the Lung Injury Prediction Score (LIPS) to help identify patients in the emergency department with high risk of developing ARDS. ARDS predictors included in the final score both triggers (ie, shock, aspiration, lung contusion) and risk modifiers (ie, smoking, diabetes mellitus, acidosis). This tool also works in hospitalized patients as a quick and effective way of identifying high-risk patients. ${ }^{55-57}$ Hopes that this score would help enrich enrollment in trials of therapeutics to decrease incidence and death from ARDS, however, have so far not borne fruit. For instance, the LIPS-A trial, in which aspirin was tested as a possible intervention in this subgroup of patients, showed no difference in rates of ARDS and rates of death after receiving aspirin versus placebo. ${ }^{58}$

Between 2001 and 2008, rates of ARDS fell by half in two ICUs in Rochester, Minnesota, in a population-based, retrospective cohort study of the epidemiology of ARDS patients admitted during that time period. Severity of acute illness, greater number of comorbidities, and major predisposing conditions in patients with ARDS increased while mortality stayed the same during this time. Interestingly, the reduction in incidence occurred exclusively in patients with hospital-acquired ARDS. As noted by the authors, during this time, a separate hospital-wide program to limit risk factors for ARDS was undertaken which can explain this reduction in hospital-acquired ARDS. This indicates that ARDS may, in part, be a preventable hospital-acquired 


\begin{tabular}{|c|c|c|c|c|}
\hline \multicolumn{5}{|c|}{$\begin{array}{l}\text { Table } 1 \\
\text { Main epidemiologic studies on ARDS incidence after AECC definition }\end{array}$} \\
\hline $\begin{array}{l}\text { Authors, } \\
\text { Year of } \\
\text { Publication } \\
\text { [Reference] } \\
\end{array}$ & $\begin{array}{l}\text { Study } \\
\text { Period }\end{array}$ & $\begin{array}{l}\text { Country or } \\
\text { Countries }\end{array}$ & $\begin{array}{l}\text { Incidence of All } \\
\text { ARDS } \\
\text { Categories (per } \\
\text { 100,000 Person- } \\
\text { Years-Population- } \\
\text { Based Studies) or } \\
\text { Percentage (\%, } \\
\text { Hospitalization- } \\
\text { Based Studies) } \\
\end{array}$ & $\begin{array}{l}\text { Incidence of } \\
\text { Moderate and } \\
\text { Severe ARDS } \\
\text { Categories (per } \\
100,000 \text { Person- } \\
\text { Years- } \\
\text { Population- } \\
\text { Based Studies) } \\
\text { or } \\
\text { Percentage (\%, } \\
\text { Hospitalization- } \\
\text { Based Studies) } \\
\end{array}$ \\
\hline $\begin{array}{l}\text { Sigurdsson } \\
\text { et al, }{ }^{15} 2013\end{array}$ & $1988-2010$ & Iceland & & $3.65-9.63$ \\
\hline $\begin{array}{l}\text { Nolan et al, }{ }^{4} \\
1997 \\
\end{array}$ & 1990-1994 & Australia & & $7.3-9.3$ \\
\hline $\begin{array}{l}\text { Luhr et al, } \\
1999\end{array}$ & 1997 & $\begin{array}{l}\text { Scandinavia } \\
\text { (Sweden, } \\
\text { Denmark, Iceland, } \\
\text { Norway) } \\
\end{array}$ & 17.9 & 13.5 \\
\hline $\begin{array}{l}\text { Bersten } \\
\quad \text { et al, }{ }^{6} 2002\end{array}$ & 1999 & $\begin{array}{l}\text { Australia (South, } \\
\text { Western, and } \\
\text { Tasmania) }\end{array}$ & 34 & 28 \\
\hline $\begin{array}{l}\text { Brun-Buisson } \\
\text { et } \mathrm{al}^{13} 2004\end{array}$ & 1999 & Europe & $\begin{array}{l}7.1 \% \text { (of all ICU } \\
\text { admissions) }\end{array}$ & $\begin{array}{l}6.1 \% \text { (of all ICU } \\
\text { admissions) }\end{array}$ \\
\hline $\begin{array}{l}\text { Rubenfeld } \\
\text { et } \mathrm{al}^{7}{ }^{7} 2005 \\
\end{array}$ & 1999-2000 & $\begin{array}{l}\text { King County, WA, } \\
\text { USA }\end{array}$ & 78.9 & 58.7 \\
\hline $\begin{array}{l}\text { Manzano et al, } \\
2005\end{array}$ & 2001 & Granada, Spain & 25.5 & 23 \\
\hline $\begin{array}{l}\text { Sakr et al, }{ }^{92} \\
2005\end{array}$ & 2002 & Europe & $\begin{array}{l}12.5 \% \text { (of all ICU } \\
\text { admissions), } \\
19.1 \% \text { (of all } \\
\text { mechanically } \\
\text { ventilated } \\
\text { patients) }\end{array}$ & $\begin{array}{l}10.6 \% \text { (of all ICU } \\
\text { admissions), } \\
16.5 \% \text { (of all } \\
\text { mechanically } \\
\text { ventilated } \\
\text { patients) } \\
\end{array}$ \\
\hline Li et al, ${ }^{9} 2011$ & $2001-2008$ & $\begin{array}{l}\text { Olmsted County, } \\
\text { MN }\end{array}$ & & $\begin{array}{l}81 \text { (in 2001), } \\
38.3 \text { (in 2008) }\end{array}$ \\
\hline $\begin{array}{l}\text { The Irish Critical } \\
\text { Care Trials } \\
\text { Group, }{ }^{14} 2008 \\
\end{array}$ & 2006 & Ireland & $19 \%$ & \\
\hline $\begin{array}{l}\text { Caser et al, }{ }^{10} \\
2014\end{array}$ & $2006-2007$ & $\begin{array}{l}\text { Vitoria Region, } \\
\text { Brazil }\end{array}$ & 10.1 & 6.3 \\
\hline $\begin{array}{l}\text { Linko et al, }{ }^{11} \\
2009\end{array}$ & 2007 & Finland & 10.6 & 5 \\
\hline $\begin{array}{l}\text { Villar et al, }{ }^{12} \\
2011\end{array}$ & $2008-2009$ & Spain & & 7.2 \\
\hline $\begin{array}{l}\text { Bellani et al, } \\
\quad 2016\end{array}$ & 2014 & 50 Countries & $\begin{array}{l}10.4 \% \text { of all ICU } \\
\text { admissions, } 5.5 \\
\text { cases per ICU bed } \\
\text { per year }\end{array}$ & \\
\hline
\end{tabular}

ARDS was defined using the Berlin definition nomenclature: All ARDS categories include mild, moderate, and severe ARDS. 
complication. ${ }^{9}$ Multiple additional studies have shown that using LTVV in all visitors to the hospital and ICU have decreased incidence of ARDS arguing for the use of LTVV in all patients and not only on those with respiratory failure. ${ }^{59,60}$

\section{ACUTE RESPIRATORY DISTRESS SYNDROME-ASSOCIATED MORTALITY}

Despite improved mortality rates, ARDS continues to be a syndrome of high mortality. As noted previously, P/F ratio correlates with ARDS outcome, prompting the authors of the Berlin Criteria to maintain the traditional severity categories in their updated consensus definition. Mortality in cohorts analyzed by the Berlin Criteria authors was $34.9 \%$ (95\% confidence interval [Cl]: $24 \%-30 \%)$ in mild ARDS, $40.3 \%$ (95\% Cl: $29 \%-34 \%$ ) in moderate ARDS, and $46.1 \%$ (95\% Cl: $29 \%-34 \%)$ in severe ARDS, as defined by P/F thresholds of 300,200 , and $100 .^{2}$ The LUNG-SAFE study reported similar findings, with 28-day mortality of $29.6 \%$ (95\% Cl: $26.2 \%-33.0 \%$ ) in mild ARDS, 35.2\% (95\% Cl: 32.4\%-38.1\%) in moderate ARDS, and $40.9 \%$ (95\% Cl: $36.8 \%-45.1 \%)$ in severe ARDS using the same P/F thresholds used in the Berlin definition. ${ }^{1}$

Reported ARDS mortality has decreased over recent decades. Compared to the late 1990s, when independent studies reported ARDS mortality of $58 \%$ to $59 \%, 4,13$ mortality in contemporary studies is much lower (Figs. 1 and 2). ARDS mortality in 2014 in LUNG-SAFE was $10.4 \%,{ }^{1}$ and $28 \%$ in the LOTUS-FRUIT U.S. multicenter study conducted by the PETAL Network in $2019 .{ }^{61}$ While imperfect, ${ }^{62}$ death certificate data also suggest decreasing risk of death for ARDS patients, with annual attributable mortality in one U.S. death certificate analysis decreasing from 5.01 per 100,000 people in 1999 to 2.82 per 100,000 population in $2013 .{ }^{63}$ While changes in ascertainment (diagnosing more patients with less-severe ARDS) and decreasing use of mechanical ventilation for patients near the end of life may contribute to this trend, it appears likely that increasing the use of LTVV since the publication of the seminal ARMA trial in 2000 is a key factor driving improved outcomes in ARDS. ${ }^{49}$ In fact, among patients who do

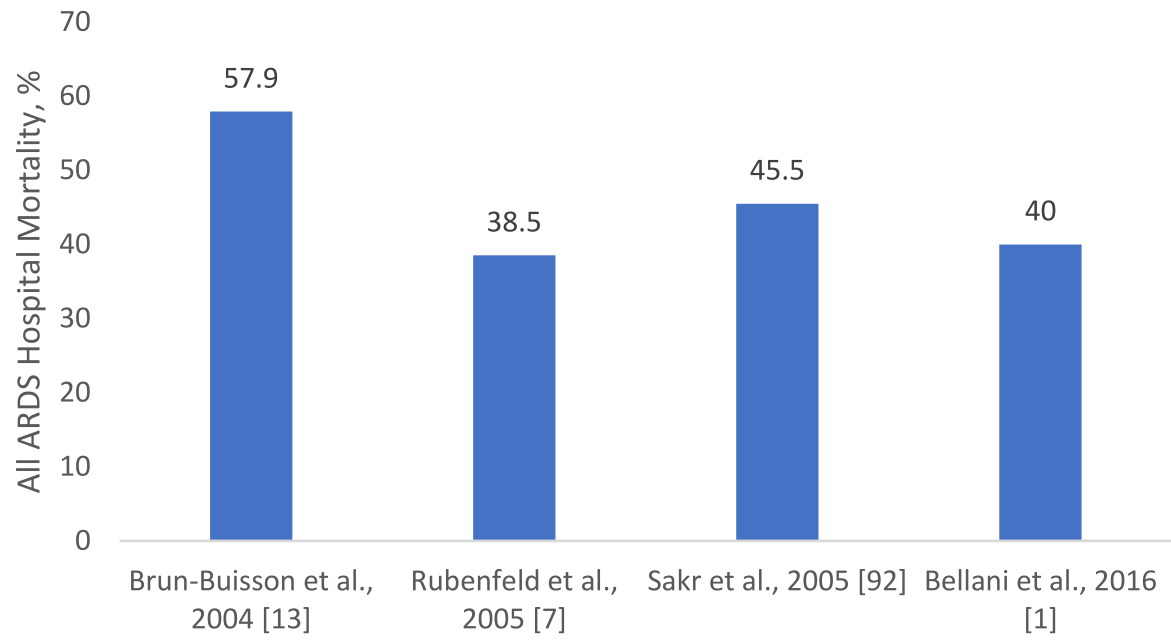

Fig. 1. Estimated overall hospital mortality rates for patients with ARDS of any severity. Hospital mortality reported in the main epidemiologic studies in all ARDS categories (mild, moderate, and severe). On the $\mathrm{X}$-axis, the studies are chronologically ordered based on the study period. 


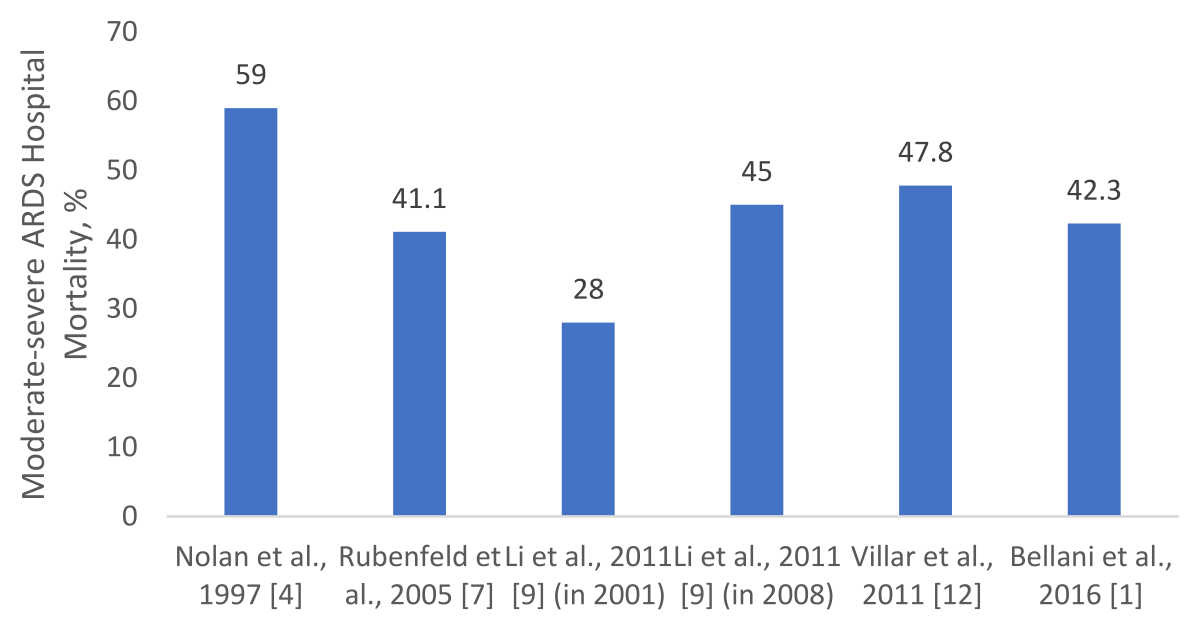

Fig. 2. Estimated mortality rates for patients with moderate-severe ARDS. Hospital mortality reported in the subgroups of moderate-severe ARDS. Moderate-severe ARDS hospital mortality in the study by Li and colleagues [2011] is reported in two different years of study, 2001 and 2008. On the X-axis, the studies are chronologically ordered based on the study period.

receive low tidal volume ventilation, there has been no change in mortality. ${ }^{64}$ It is also important to note that, in some settings, apparent stability of crude ARDS mortality may mask changes in case mix (increasing illness severity and comorbidities) and therefore improving risk-adjusted mortality. ${ }^{9}$

\section{LONG-TERM OUTCOMES}

Despite the significant lung injury experienced during the course of a patient's illness with ARDS, postillness pulmonary function tests showed normalization at 5 years after ICU. ${ }^{65}$ Despite this normalization in lung function, reported quality-of-life scores and exercise tolerance, measured by 6 -minute walk test, remain lower than average at 5 years. Multiple factors likely contribute to this including persistent weakness and neuropsychologic impairments. These neuropsychologic issues are heterogeneous and affect both the patient and their caregivers. ${ }^{65}$ These patients also accrue larger health care costs after hospitalization because of increased utilization of the health care system. ARDS is one of the most common reasons for admission to a longterm ventilator rehabilitation unit. $^{66}$

\section{COVID-19}

The severe acute respiratory distress syndrome-associated coronavirus- 2 was first identified in December 2019 in Wuhan, Hubei, China, as the agent causing what is now called COVID-19. ${ }^{67}$ COVID-19 was officially declared a pandemic by the World Health Organization on March 11, 2020. As of November 21, 2020, 57,274,018 confirmed cases have been reported with $1,368,000$ deaths worldwide. ${ }^{68}$ While it is increasingly clear that COVID-19 is a multisystem disease, the primary manifestation is a viral pneumonia that, in some patients, progresses to ARDS, often complicated by protracted illness or death.

Mortality estimates for COVID-19-associated ARDS vary widely, ranging from $3.4 \%$ to $88.3 \%$ (Table 2). ${ }^{69-74}$ These estimates are affected by the studied population, 


\begin{tabular}{|c|c|c|c|}
\hline \multicolumn{4}{|c|}{$\begin{array}{l}\text { Table } 2 \\
\text { Twenty-eight-day mortality rate data of patients with ARDS from COVID-19 }\end{array}$} \\
\hline $\begin{array}{l}\text { Authors, Year of } \\
\text { Publication } \\
\text { [Reference] }\end{array}$ & Study Period & City, Country & Mortality \\
\hline Yang et $\mathrm{al}_{,}{ }^{69} 2020$ & $12 / 24 / 2019-01 / 26 / 2020$ & Wuhan, China & $61.5 \%$ \\
\hline Wang et $\mathrm{al}^{70} 2020$ & $01 / 25 / 2020-02 / 25 / 2020$ & Shanghai, China & $88.3 \%$ \\
\hline Grasselli et al, ${ }^{71} 2020$ & $02 / 20 / 2020-03 / 18 / 2020$ & Milan, Italy & $26 \%$ \\
\hline Ferrando et al, ${ }^{72} 2020$ & $03 / 12 / 2020-06 / 01 / 2020$ & Spain and Andora & $36 \%$ \\
\hline Bhatraju et $\mathrm{al}{ }^{74} 2020$ & 02/24/2020-03/09/2020 & Seattle, USA & $50 \%$ * \\
\hline Gupta et al $^{73} 2020$ & $03 / 04 / 2020-04 / 04 / 2020$ & Various cities, USA & $\begin{array}{c}6.6 \%-80.8 \% \\
(35.4 \%)\end{array}$ \\
\hline
\end{tabular}

All patients were admitted to the ICU with ARDS due to COVID-19. All mortalities are 28-d mortality except the study by *Batraju et al which includes a 14-d mortality.

health system factors (thresholds for hospitalization varied across cohorts substantially), therapeutic context (Early in the pandemic, large numbers of potentially toxic therapies were administered in cocktails.), institutional context (the degree to which the studied health care systems were strained by the pandemic surge), and patientlevel risk factors (some sites predominantly cared for patients in nursing homes). For example, patients admitted to hospitals with fewer ICU beds had higher risk of death likely because of less training and comfort of caregivers in treating ARDS as well as limited resources in these settings, particularly in the pandemic context. Critically, some early mortality studies had insufficient follow-up to provide accurate estimates of morality, excluding patients without a final outcome (discharge or death) and thereby inflating mortality estimates by excluding patients alive and still in the hospital.

The question of whether and how COVID-19-associated ARDS differs from prior forms of ARDS has been surprisingly contentious. ${ }^{75}$ Early anxiety about abrupt decompensation specific to this condition, the risk of aerosolization and consequent transmission to caregivers with high-flow nasal cannula oxygen, and lack of effective therapeutics all played a role, as did clinician perceptions that some patients with COVID-19 exhibit "happy hypoxemia" and/or higher-than-expected lung compliance for their degree of hypoxemia. ${ }^{76}$ The opinion that ARDS resulting from COVID-19 might be exceptional and clinicians' frustration over the lack of proven treatments were sometimes associated with calls for application of therapies previously shown ineffective in general ARDS and even for the use of high-tidal-volume ventilation. Spring and summer 2020 witnessed a vigorous debate on the issues, with some thought leaders arguing for novel supportive care, and others arguing that standard supportive care for ARDS represented the best approach. ${ }^{77,78}$

While some prognostic factors differ and time from COVID-19 symptom onset to full ARDS is sometimes slightly longer than with some classic ARDS etiologies, ${ }^{79}$ most evidence to date suggests that ARDS in COVID-19 lacks important differences from the syndrome generally. Contradicting the postulated "L-type" (high compliance) and "Htype" (low compliance) dichotomy advanced by some as unique to COVID-19 ARDS, ${ }^{76,80}$ the spectrum of lung compliance in COVID-19 ARDS appears similar to that observed in prior studies of general ARDS. ${ }^{81}$ Pathologic analysis also shows findings similar to ARDS generally, demonstrating hyaline membrane formation, edema, and DAD. ${ }^{82}$ We therefore manage COVID-19 ARDS with the package of evidencebased care that we apply to ARDS generally, including strict adherence to low-tidalvolume ventilation, ${ }^{49}$ consideration of prone positioning, ${ }^{83}$ and high PEEP for more 
severe ARDS, ${ }^{36}$ conservative fluid management, ${ }^{84}$ protocolized spontaneous breathing and awakening trial, ${ }^{85}$ and early mobilization. ${ }^{86}$ It is nevertheless plausible that, given its homogeneous trigger and potentially more homogeneous inflammatory phenotype, ARDS resulting from COVID-19 could respond to therapies that failed trials enrolling patients with a heterogeneous array of triggers and endotypes. The apparent efficacy of steroid therapy in several (imperfect) trials, ${ }^{87,88}$ a treatment for which trials in general ARDS population had repeatedly yielded conflicting evidence, ${ }^{89-91}$ may be one early example of this phenomenon.

\section{SUMMARY}

ARDS remains a common, deadly problem among critically ill patients around the world. It is a syndrome of significant heterogeneity, with sub-phenotypes requiring further characterization and tools for prompt clinical identification. COVID-19 has brought new challenges including a large, and relatively homogeneous, population of ARDS patients but does not seem to cause a truly unique respiratory failure syndrome distinct from ARDS generally nor even engender a truly homogenous subtype of ARDS. Further advances in ARDS care will likely require improved understanding of the epidemiology of this syndrome and its subtypes as well as innovative trials of focused therapeutics. Given the high mortality of the syndrome and its long-term morbidity, ongoing study into treatment and care of patients with ARDS is paramount.

\section{CLINICS CARE POINTS}

- Although acute respiratory distress syndrome (ARDS) has a high incidence among intensive care unit patients, with high morbidity and mortality, it remains underdiagnosed.

- The Berlin criteria were created to help clearly identify patients with ARDS.

- Supportive measures with low-tidal-volume ventilation, prone positioning, conservative fluid management strategies, high PEEP for severe disease, protocolized spontaneous breathing and awakening trials, and early mobilization have lowered the morbidity and mortality of ARDS and are the cornerstone of therapy.

- COVID-19-associated ARDS is a syndrome on the ARDS spectrum and should therefore be treated with the same strategies as classic ARDS while we await results of ongoing trials.

\section{DISCLOSURE}

K.W. Hendrickson declares no disclosures. I.D. Peltan reports receiving research support from the National Institutes of Health, Centers for Disease Control, Janssen Pharmaceuticals, and Immunexpress, Inc. and support to institution from Regeneron and Asahi Kasei Pharma. S.M. Brown-please see pdf in Other Content tab.

\section{REFERENCES}

1. Bellani G, et al. Epidemiology, patterns of care, and mortality for patients with acute respiratory distress syndrome in intensive care units in 50 countries. JAMA 2016;315(8):788-800.

2. Force ADT, et al. Acute respiratory distress syndrome: the Berlin definition. JAMA 2012;307(23):2526-33.

3. Ashbaugh DG, et al. Acute respiratory distress in adults. Lancet 1967;2(7511): 319-23. 
4. Nolan S, et al. Acute respiratory distress syndrome in a community hospital ICU. Intensive Care Med 1997;23(5):530-8.

5. Luhr OR, et al. Incidence and mortality after acute respiratory failure and acute respiratory distress syndrome in Sweden, Denmark, and Iceland. The ARF Study Group. Am J Respir Crit Care Med 1999;159(6):1849-61.

6. Bersten AD, et al. Incidence and mortality of acute lung injury and the acute respiratory distress syndrome in three Australian States. Am J Respir Crit Care Med 2002; 165(4):443-8.

7. Rubenfeld GD, et al. Incidence and outcomes of acute lung injury. N Engl J Med 2005;353(16):1685-93.

8. Manzano F, et al. Incidence of acute respiratory distress syndrome and its relation to age. J Crit Care 2005;20(3):274-80.

9. Li G, et al. Eight-year trend of acute respiratory distress syndrome: a populationbased study in Olmsted County, Minnesota. Am J Respir Crit Care Med 2011; 183(1):59-66.

10. Caser EB, et al. Impact of distinct definitions of acute lung injury on its incidence and outcomes in Brazilian ICUs: prospective evaluation of 7,133 patients*. Crit Care Med 2014;42(3):574-82.

11. Linko R, et al. Acute respiratory failure in intensive care units. FINNALI: a prospective cohort study. Intensive Care Med 2009;35(8):1352-61.

12. Villar J, et al. The ALIEN study: incidence and outcome of acute respiratory distress syndrome in the era of lung protective ventilation. Intensive Care Med 2011;37(12):1932-41.

13. Brun-Buisson C, et al. Epidemiology and outcome of acute lung injury in European intensive care units. Results from the ALIVE study. Intensive Care Med 2004;30(1):51-61.

14. Irish Critical Care Trials, G. Acute lung injury and the acute respiratory distress syndrome in Ireland: a prospective audit of epidemiology and management. Crit Care 2008;12(1):R30.

15. Sigurdsson MI, et al. Acute respiratory distress syndrome: nationwide changes in incidence, treatment and mortality over 23 years. Acta Anaesthesiol Scand 2013; 57(1):37-45.

16. Bachofen M, Weibel ER. Structural alterations of lung parenchyma in the adult respiratory distress syndrome. Clin Chest Med 1982;3(1):35-56.

17. Tomashefski JF Jr. Pulmonary pathology of the adult respiratory distress syndrome. Clin Chest Med 1990;11(4):593-619.

18. Hoelz C, et al. Morphometric differences in pulmonary lesions in primary and secondary ARDS. A preliminary study in autopsies. Pathol Res Pract 2001;197(8): 521-30.

19. Moss M, et al. Diabetic patients have a decreased incidence of acute respiratory distress syndrome. Crit Care Med 2000;28(7):2187-92.

20. Rubenfeld GD, Herridge MS. Epidemiology and outcomes of acute lung injury. Chest 2007;131(2):554-62.

21. Ni YN, et al. Can body mass index predict clinical outcomes for patients with acute lung injury/acute respiratory distress syndrome? A meta-analysis. Crit Care 2017;21(1):36.

22. Zhi G, et al. Obesity paradox" in acute respiratory distress syndrome: asystematic review and meta-analysis. PLoS One 2016;11(9):e0163677.

23. McCallister JW, Adkins EJ, O’Brien JM Jr. Obesity and acute lung injury. Clin Chest Med 2009;30(3):495-508, viii. 
24. Stensrud MJ, Valberg M, Aalen OO. Can collider bias explain paradoxical associations? Epidemiology 2017;28(4):e39-40.

25. Kaphalia L, Calhoun WJ. Alcoholic lung injury: metabolic, biochemical and immunological aspects. Toxicol Lett 2013;222(2):171-9.

26. Calfee CS, et al. Cigarette smoke exposure and the acute respiratory distress syndrome. Crit Care Med 2015;43(9):1790-7.

27. Hsieh SJ, et al. Prevalence and impact of active and passive cigarette smoking in acute respiratory distress syndrome. Crit Care Med 2014;42(9):2058-68.

28. Ware LB, et al. Long-term ozone exposure increases the risk of developing the acute respiratory distress syndrome. Am J Respir Crit Care Med 2016;193(10): 1143-50.

29. Erickson SE, et al. Racial and ethnic disparities in mortality from acute lung injury. Crit Care Med 2009;37(1):1-6.

30. Meyer NJ, Christie JD. Genetic heterogeneity and risk of acute respiratory distress syndrome. Semin Respir Crit Care Med 2013;34(4):459-74.

31. Laffey JG, et al. Potentially modifiable factors contributing to outcome from acute respiratory distress syndrome: the LUNG SAFE study. Intensive Care Med 2016; 42(12):1865-76.

32. Calfee CS, et al. Trauma-associated lung injury differs clinically and biologically from acute lung injury due to other clinical disorders. Crit Care Med 2007; 35(10):2243-50.

33. Tejera $P$, et al. Distinct and replicable genetic risk factors for acute respiratory distress syndrome of pulmonary or extrapulmonary origin. J Med Genet 2012; 49(11):671-80.

34. Villar J, et al. A universal definition of ARDS: the PaO2/FiO2 ratio under a standard ventilatory setting-a prospective, multicenter validation study. Intensive Care Med 2013;39(4):583-92.

35. Thille AW, et al. Comparison of the Berlin definition for acute respiratory distress syndrome with autopsy. Am J Respir Crit Care Med 2013;187(7):761-7.

36. Guo L, et al. Higher PEEP improves outcomes in ARDS patients with clinically objective positive oxygenation response to PEEP: a systematic review and meta-analysis. BMC Anesthesiol 2018;18(1):172.

37. Brower RG, et al. Higher versus lower positive end-expiratory pressures in patients with the acute respiratory distress syndrome. N Engl J Med 2004;351(4): 327-36.

38. Meade $\mathrm{MO}$, et al. Ventilation strategy using low tidal volumes, recruitment maneuvers, and high positive end-expiratory pressure for acute lung injury and acute respiratory distress syndrome: a randomized controlled trial. JAMA 2008; 299(6):637-45.

39. Mercat A, et al. Positive end-expiratory pressure setting in adults with acute lung injury and acute respiratory distress syndrome: a randomized controlled trial. JAMA 2008;299(6):646-55.

40. Papazian L, et al. Neuromuscular blockers in early acute respiratory distress syndrome. N Engl J Med 2010;363(12):1107-16.

41. National Heart L, et al. Early neuromuscular blockade in the acute respiratory distress syndrome. N Engl J Med 2019;380(21):1997-2008.

42. Shaver CM, Bastarache JA. Clinical and biological heterogeneity in acute respiratory distress syndrome: direct versus indirect lung injury. Clin Chest Med 2014; 35(4):639-53. 
43. Bernard GR, et al. The American-European Consensus Conference on ARDS. Definitions, mechanisms, relevant outcomes, and clinical trial coordination. Am J Respir Crit Care Med 1994;149(3 Pt 1):818-24.

44. Pelosi P, et al. Pulmonary and extrapulmonary acute respiratory distress syndrome are different. Eur Respir J Suppl 2003;42:48s-56s.

45. Gattinoni L, et al. Acute respiratory distress syndrome caused by pulmonary and extrapulmonary disease. Different syndromes? Am J Respir Crit Care Med 1998; 158(1):3-11.

46. Albaiceta GM, et al. Differences in the deflation limb of the pressure-volume curves in acute respiratory distress syndrome from pulmonary and extrapulmonary origin. Intensive Care Med 2003;29(11):1943-9.

47. Calfee CS, et al. Distinct molecular phenotypes of direct vs indirect ARDS in single-center and multicenter studies. Chest 2015;147(6):1539-48.

48. Agarwal R, et al. Is the mortality higher in the pulmonary vs the extrapulmonary ARDS? A meta analysis. Chest 2008;133(6):1463-73.

49. Acute Respiratory Distress Syndrome, N, et al. Ventilation with lower tidal volumes as compared with traditional tidal volumes for acute lung injury and the acute respiratory distress syndrome. N Engl J Med 2000;342(18):1301-8.

50. Calfee CS, et al. Subphenotypes in acute respiratory distress syndrome: latent class analysis of data from two randomised controlled trials. Lancet Respir Med 2014;2(8):611-20.

51. Calfee CS, et al. Acute respiratory distress syndrome subphenotypes and differential response to simvastatin: secondary analysis of a randomised controlled trial. Lancet Respir Med 2018;6(9):691-8.

52. Pham T, Rubenfeld GD. Fifty years of research in ARDS. The epidemiology of acute respiratory distress syndrome. A 50th birthday review. Am J Respir Crit Care Med 2017;195(7):860-70.

53. Ferguson ND, et al. Acute respiratory distress syndrome: underrecognition by clinicians and diagnostic accuracy of three clinical definitions. Crit Care Med 2005; 33(10):2228-34.

54. Frohlich S, et al. Acute respiratory distress syndrome: underrecognition by clinicians. J Crit Care 2013;28(5):663-8.

55. Gajic $\mathrm{O}$, et al. Early identification of patients at risk of acute lung injury: evaluation of lung injury prediction score in a multicenter cohort study. Am J Respir Crit Care Med 2011;183(4):462-70.

56. Trillo-Alvarez C, et al. Acute lung injury prediction score: derivation and validation in a population-based sample. Eur Respir J 2011;37(3):604-9.

57. Soto GJ, et al. Lung injury prediction score in hospitalized patients at risk of acute respiratory distress syndrome. Crit Care Med 2016;44(12):2182-91.

58. Kor DJ, et al. Effect of aspirin on development of ARDS in at-risk patients presenting to the emergency department: the LIPS-A randomized clinical trial. JAMA 2016;315(22):2406-14.

59. Serpa Neto A, et al. Association between use of lung-protective ventilation with lower tidal volumes and clinical outcomes among patients without acute respiratory distress syndrome: a meta-analysis. JAMA 2012;308(16):1651-9.

60. Writing Group for the, P.I, et al. Effect of a low vs intermediate tidal volume strategy on ventilator-free days in intensive care unit patients without ARDS: a randomized clinical trial. JAMA 2018;320(18):1872-80.

61. Lanspa MJ, et al. Prospective assessment of the feasibility of a trial of low-tidal volume ventilation for patients with acute respiratory failure. Ann Am Thorac Soc 2019;16(3):356-62. 
62. Falci L, et al. Examination of cause-of-death data quality among New York city deaths due to cancer, pneumonia, or diabetes from 2010 to 2014. Am J Epidemiol 2018;187(1):144-52.

63. Cochi SE, et al. Mortality trends of acute respiratory distress syndrome in the United States from 1999 to 2013. Ann Am Thorac Soc 2016;13(10):1742-51.

64. Walkey AJ, et al. Acute respiratory distress syndrome: epidemiology and management approaches. Clin Epidemiol 2012;4:159-69.

65. Herridge MS, et al. Functional disability 5 years after acute respiratory distress syndrome. N Engl J Med 2011;364(14):1293-304.

66. Mamary AJ, et al. Survival in patients receiving prolonged ventilation: factors that influence outcome. Clin Med Insights Circ Respir Pulm Med 2011;5:17-26.

67. Zhu N, et al. A novel coronavirus from patients with pneumonia in China, 2019. N Engl J Med 2020;382(8):727-33.

68. Available at: https://www.who.int/emergencies/diseases/novel-coronavirus-2019? gclid=EAlalQobChMloNWJg6m86wIVjcDACh2RZAFnEAAYASAAEgl7APD_BwE. Accessed August 27, 2020.

69. Yang $X$, et al. Clinical course and outcomes of critically ill patients with SARSCoV-2 pneumonia in Wuhan, China: a single-centered, retrospective, observational study. Lancet Respir Med 2020;8(5):475-81.

70. Wang $Y$, et al. Clinical course and outcomes of 344 intensive care patients with COVID-19. Am J Respir Crit Care Med 2020;201(11):1430-4.

71. Grasselli G, et al. Baseline characteristics and outcomes of 1591 patients infected with SARS-CoV-2 admitted to ICUs of the Lombardy region, Italy. JAMA 2020;323(16):1574-81.

72. Ferrando C, et al. Clinical features, ventilatory management, and outcome of ARDS caused by COVID-19 are similar to other causes of ARDS. Intensive Care Med 2020;46(12):2200-11.

73. Gupta S, et al. Factors associated with death in critically ill patients with coronavirus disease 2019 in the US. JAMA Intern Med 2020;180(11):1436-47.

74. Bhatraju PK, et al. Covid-19 in critically ill patients in the seattle region - case series. N Engl J Med 2020;382(21):2012-22.

75. Barbeta E, et al. SARS-CoV-2-induced acute respiratory distress syndrome: pulmonary mechanics and gas-exchange abnormalities. Ann Am Thorac Soc 2020; 17(9):1164-8.

76. Marini JJ, Gattinoni L. Management of COVID-19 respiratory distress. JAMA 2020;323(22):2329-30.

77. Matthay MA, Aldrich JM, Gotts JE. Treatment for severe acute respiratory distress syndrome from COVID-19. Lancet Respir Med 2020;8(5):433-4.

78. Wiersinga WJ, et al. Pathophysiology, transmission, diagnosis, and treatment of coronavirus disease 2019 (COVID-19): a review. JAMA 2020;324(8):782-93.

79. Li X, Ma X. Acute respiratory failure in COVID-19: is it "typical" ARDS? Crit Care 2020;24(1):198.

80. Gattinoni L, et al. COVID-19 pneumonia: different respiratory treatments for different phenotypes? Intensive Care Med 2020;46(6):1099-102.

81. Panwar R, et al. Compliance phenotypes in early acute respiratory distress syndrome before the COVID-19 pandemic. Am J Respir Crit Care Med 2020;202(9): 1244-52.

82. Calabrese F, et al. Pulmonary pathology and COVID-19: lessons from autopsy. The experience of European Pulmonary Pathologists. Virchows Arch 2020; 477(3):359-72. 
83. Guerin C, Reignier J, Richard JC. Prone positioning in the acute respiratory distress syndrome. N Engl J Med 2013;369(10):980-1.

84. National Heart L, et al. Comparison of two fluid-management strategies in acute lung injury. N Engl J Med 2006;354(24):2564-75.

85. Girard TD, et al. Efficacy and safety of a paired sedation and ventilator weaning protocol for mechanically ventilated patients in intensive care (Awakening and Breathing Controlled trial): a randomised controlled trial. Lancet 2008; 371(9607):126-34.

86. Taito $\mathrm{S}$, et al. Early mobilization of mechanically ventilated patients in the intensive care unit. J Intensive Care 2016;4:50.

87. RECOVERY Collaborative Group, Horby P, Lim WS, et al. Dexamethasone in hospitalized patients with Covid-19. N Engl J Med 2021;384(8):693-704. https://doi. org/10.1056/NEJMoa2021436.

88. Prescott HC, Rice TW. Corticosteroids in COVID-19 ARDS: evidence and Hope during the pandemic. JAMA 2020;324(13):1292-5.

89. Schein RM, et al. Complement activation and corticosteroid therapy in the development of the adult respiratory distress syndrome. Chest 1987;91(6):850-4.

90. Peter JV, et al. Corticosteroids in the prevention and treatment of acute respiratory distress syndrome (ARDS) in adults: meta-analysis. BMJ 2008;336(7651): 1006-9.

91. Villar J, et al. Dexamethasone treatment for the acute respiratory distress syndrome: a multicentre, randomised controlled trial. Lancet Respir Med 2020; 8(3):267-76.

92. Sakr $Y$, et al. High tidal volume and positive fluid balance are associated with worse outcome in acute lung injury. Chest 2005;128(5):3098-108. 